\title{
Effect of hemoglobin concentration on oxyhemoglobin dissociation during hypothermic blood cardioplegic arrest
}

\begin{abstract}
Background: This study compares oxyhemoglobin dissociation during the nonperfused periods of hypothermic cardioplegic arrest in two blood cardioplegic solutions with different hemoglobin concentrations. The hypothesis is that more oxygen will dissociate from hemoglobin in a blood cardioplegic solution with a higher hemoglobin content than from a cardioplegic solution with a lower hemoglobin content. However, the increment in the volume of oxygen that dissociates from hemoglobin will be less than anticipated by a ratio of hemoglobin concentrations in the cardioplegic solution. Methods and results: Pigs $(n=22)$ were supported by bypass and subjected to 60 minutes of hypothermic cardioplegic arrest with either a high-hemoglobin $(n=10)$ or low-hemoglobin $(n=12)$ blood cardioplegic solution. Aortic root and coronary sinus blood samples were obtained before bypass and 5 seconds after the start of cardioplegic infusions at 20, 40, and 60 minutes of cardioplegic arrest. Oxyhemoglobin dissociation occurred in both experimental groups during the ischemic intervals of cardioplegic arrest. However, there were no significant differences between the high- and low-hemoglobin groups in the arterial-venous oxygen content differences for samples taken after each of the three ischemic intervals ( $p$ values: control $=0.78$; cardioplegia interval $1=0.95$; interval $2=0.56$; and interval $3=0.12$ ). Conclusions: The present study emphasizes the inherent limitations of unmodified erythrocyte hemoglobin as an oxygen source in hypothermic alkalotic cardioplegic solutions. These limitations may be obviated by methods that increase the dissolved oxygen content of the cardioplegic solution or methods that decrease the affinity of hemoglobin for oxygen under conditions of hypothermia and alkalosis. (J ThoraC CaRdiovasC SURG 1994;108:664-71)
\end{abstract}

William L. Holman, MD, Walter V. A. Vicente, MD, PhD, Russell D. Spruell, BSEE, Stanley B. Digerness, PhD, and Albert D. Pacifico, MD, Birmingham, Ala.

xygenation of hypothermic cardioplegic solutions is generally accepted as a means to enhance aerobic metabolism during ischemic (i.e., nonperfused) periods of car-

From the Department of Surgery, University of Alabama at Birmingham, and Birmingham Veterans Administration Medical Center, Birmingham, Ala.

Supported by U.S. Public Health Service grant HL 43213 and a grant from CNPq Conselho Nacional de Desenvolvimento Cientifico e Tecnologico, Brazil. This work was performed during Dr. Holman's tenure as an Established Investigator for the American Heart Association.

Received for publication Oct. 13, 1993.

Accepted for publication Jan. 9, 1994.

Address for reprints: William L. Holman, MD, Department of Surgery, University of Alabama at Birmingham, University Station, Bir-

- mingham, AL 35294

$12 / 1 / 54526$ dioplegic arrest and thus optimize postcardioplegia cardiac function. Previous experiments from this laboratory ${ }^{1}$ have demonstrated that oxygen dissociates from hemoglobin during the ischemic intervals of cardioplegic arrest. However, the only oxygen taken up by the myocardium during infusion of blood cardioplegic solution is oxygen dissolved in the cardioplegic solution. These observations are presumably related to the high affinity of hemoglobin for oxygen in a hypothermic alkalotic solution. The present study represents an extension of this previous work.

Other investigators have examined additional aspects of oxygen delivery from hypothermic blood cardioplegic solutions and have made the following observations: postischemic recovery of mechanical function is independent of the hematocrit value in a hypothermic blood cardioplegic solution across a range of $10 \%$ to $20 \%^{2}$; the 
Table I. Components of blood cardioplegia solution

\begin{tabular}{cc}
\hline Crystalloid component & Final BCP solution \\
\hline $\mathrm{KCl}(2 \mathrm{mmol} / \mathrm{ml}), 5 \mathrm{ml}$ or & $\mathrm{K}^{+}=8-10$ or $22-25$ \\
$20 \mathrm{ml}$ & $\mathrm{mmol} / \mathrm{L}$ \\
Tham $(0.3 \mathrm{~mol}) 100 \mathrm{ml}$ & $\mathrm{pH}=7.7-7.8$ \\
$\mathrm{CPD}, 25 \mathrm{ml}$ & $\mathrm{Ca}^{++}=0.5-0.7 \mathrm{mmol} / \mathrm{L}$ \\
$\mathrm{D}_{5} 1 / 4 \mathrm{NS}, 275 \mathrm{ml}$ & Osm $=340-360 \mathrm{mOsm} / \mathrm{kg}$ \\
& water
\end{tabular}

The blood cardioplegic solution was composed of a crystalloid component that was mixed with blood from the pump-oxygenator at a ratio of four parts blood to one part crystalloid component. The initial 3-minute infusion of the cardioplegic solution and the $38^{\circ} \mathrm{C}$ cardioplegic solution that was administered at the end of the ischemic interval contained a higher concentration of potassium ( 22 to $25 \mathrm{mmol} /$ L) and is referred to as solution I. A lower dose potassium solution (8 to 10 $\mathrm{mmol} / \mathrm{L}$ ) was used for the cardioplegic infusion at 20 and 40 minutes of ischemia. This solution is referred to as solution II. $B C P$, Blood cardioplegia; Tham, tromethamine; $C P D$, citrate-phosphate-dextrose; $D_{5}, 5 \%$ dextrose; $N S$, normal saline.

erythrocyte component of a blood cardioplegic solution has non-oxygen-related beneficial effects that may be as important as the oxygen-carrying capacity of hemoglo$\mathrm{bin}^{3-5}$; lower temperatures diminish the benefit of an oxygenated blood cardioplegic solution relative to an oxygenated crystalloid cardioplegic solution ${ }^{6,7}$; and supplemental dissolved oxygen (e.g., in cardioplegic solutions containing a perfluorocarbon emulsion) increases aerobic metabolism and improves myocardial protection during hypothermic cardioplegic arrest in comparison with oxygenated crystalloid or blood cardioplegic solutions. ${ }^{8-14}$

The purpose of the present study is to compare oxyhemoglobin dissociation during the nonperfused periods of hypothermic cardioplegic arrest in two blood cardioplegic solutions with different hemoglobin concentrations. The hypothesis of the study is that more oxygen will dissociate from hemoglobin in a blood cardioplegic solution with a higher hemoglobin content than from a cardioplegic solution with a lower hemoglobin content. However, the increment in oxygen dissociation will be less than anticipated by a simple ratio of hemoglobin concentrations in the cardioplegic solution.

\section{Methods}

Experimental protocol. The methods used in this study were similar to those used in a previous study from this laboratory. ${ }^{1}$ Twenty-two pigs of both sexes weighing from 18 to $30 \mathrm{~kg}$ were sedated, then intubated, and their lungs mechanically ventilated with a mixture of oxygen and nitrous oxide in a ratio of 1:2. Pentobarbital and pancuronium bromide were administered as a constant infusion to maintain anesthesia. Arterial blood gas measurements were obtained periodically throughout the study, and the $\mathrm{pH}$ and carbon dioxide tension $\left(\mathrm{PCO}_{2}\right)$ were maintained within physiologic range. After intubation and during cardiopulmonary bypass, systemic arterial oxygen tensions $\left(\mathrm{PO}_{2}\right)$ ranged from 100 to $500 \mathrm{~mm} \mathrm{Hg}$.

The heart was exposed through a median sternotomy and the hemiazygos vein was ligated immediately before it entered the

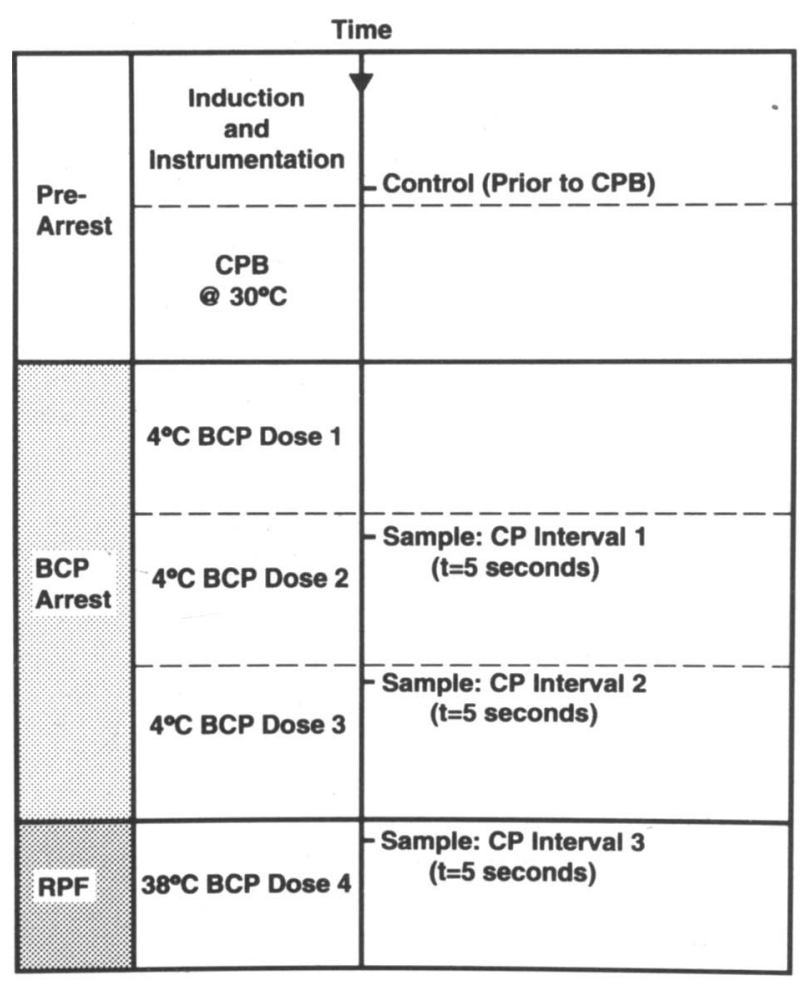

Fig. 1. The timing of blood samples is illustrated in this summary of the experimental protocol. $C P B$, Cardiopulmonary bypass; $B C P$, blood cardioplegia; $R P F$, reperfusion; $C P$, cardioplegia.

coronary sinus. After heparin $300 \mathrm{U} / \mathrm{kg}$ was administered, a coronary sinus catheter with an occlusive inflatable balloon was inserted through the right atrial wall into the proximal portion of the coronary sinus. The latex balloon was inflated during ischemia and prevented contamination of the coronary sinus blood sample by right atrial blood. However, it took 3 to $5 \mathrm{sec}-$ onds after the start of the cardioplegic infusion to establish sufficient coronary sinus flow to allow blood sampling. Therefore, 5 seconds after infusion of the blood cardioplegic solution was begun, $3 \mathrm{ml}$ of coronary sinus blood was gently withdrawn from the coronary sinus catheter and discarded; then another $2 \mathrm{ml}$ sample was obtained for analysis. Immediately after this blood sample had been obtained, the coronary sinus balloon was deflated.

A thermistor (model NTM-100 Digital Thermometer, Webster Laboratories, Inc., Baldwin Park, Calif.) was placed in the anterior ventricular septum, and the aorta and right atrium were cannulated for cardiopulmonary bypass. Cardiopulmonary bypass was initiated at $30^{\circ} \mathrm{C}$. During initial cooling a left ventricular vent, aortic root cardioplegia infusion catheter, and aortic root pressure monitoring line were placed. The limb lead electrocardiogram, systemic blood pressure, and aortic root pressure signals were amplified (amplifier models 20-4615-58, 13-G4615-64A, and 13-G4615-50, Gould Electronics, Cleveland, Ohio) and recorded (strip chart recorder model 1400 , Gould Electronics, Cleveland, Ohio).

A bubble oxygenator (model Bentley-5 oxygenator, Ameri- 


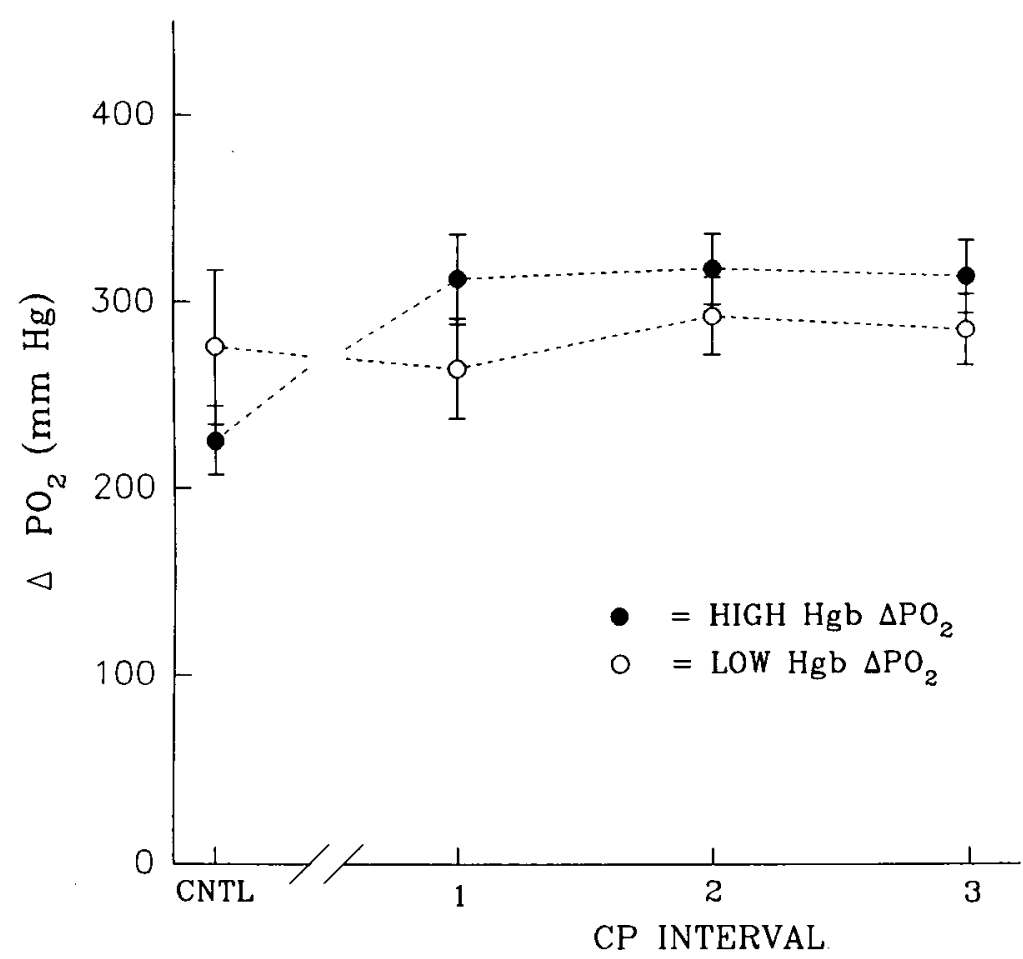

Fig. 2. The transmyocardial gradient for dissolved oxygen (i.e., the $\mathrm{PO}_{2}$ gradient) did not show any statistically significant differences between the two experimental groups, although there was a trend for higher $\mathrm{PO}_{2}$ gradients for the high-hemoglobin group during cardioplegic arrest. $\left(\Delta \mathrm{PO}_{2}=\right.$ Aortic root - coronary sinus $\left.\mathrm{PO}_{2}\right) . C N T L$, Control; $H g b$, hemoglobin.

can Bentley Corp., Irvine, Calif.) was used together with standard roller pumps to deliver a systemic flow of 2.0 to 2.2 $\mathrm{L} / \mathrm{min} /$ per square meter at $37^{\circ}$ to $38^{\circ} \mathrm{C}$ and 1.8 to $2.0 \mathrm{~L} / \mathrm{min}$ per square meter at $30^{\circ} \mathrm{C}$. After blood samples had been obtained before cardiopulmonary bypass (control), the aorta was crossclamped and cold $\left(4^{\circ} \mathrm{C}\right)$ high-hemoglobin $(n=10$ pigs) or low-hemoglobin ( $n=12$ pigs) cardioplegic solution I $\left(\mathrm{K}^{+}=22\right.$ to $\left.25 \mathrm{mmol} / \mathrm{L}\right)$ was infused into the aortic root at a pressure of 60 to $70 \mathrm{~mm} \mathrm{Hg}$ with a calibrated roller pump linked to the data acquisition system via an optical tachometer (model 8200-50 Cole-Parmer, Chicago, Ill.). The initial infusion of blood cardioplegic solution lasted for 3 minutes. Doses of highor low-hemoglobin cardioplegic solution II $\left(\mathrm{K}^{+}=8\right.$ to 10 $\mathrm{mmol} / \mathrm{L}$ ) were given at 20 and 40 minutes of ischemia. These two doses were 1 minute in duration. Blood samples were taken at 5 seconds during each of these cardioplegic infusions (samples at 20 and 40 minutes are listed as cardioplegia intervals 1 and 2). Topical iced saline slush was used to maintain the septal temperature below $15^{\circ} \mathrm{C}$. At 60 minutes, all topical slush was removed from the pericardial space and an infusion of $38^{\circ} \mathrm{C}$ high- or low-hemoglobin cardioplegic solution I (cardioplegia dose $=500 \mathrm{ml} / \mathrm{m}^{2}$ ) was begun at a mean pressure of 60 to 70 $\mathrm{mm} \mathrm{Hg}$. A sample drawn at 5 seconds during this infusion is listed as cardioplegia interval 3.

The blood cardioplegic solution is a buffered, hyperkalemic, hypocalcemic solution based on a formula developed by Buckberg (Table I). The crystalloid component of the cardioplegic solution was mixed with blood from the pump-oxygenator at a
4:1 blood/crystalloid ratio. Additional blood for the highhemoglobin cardioplegia group was obtained immediately before the study from heparinized, ventilated, and anesthetized pigs. The $\mathrm{pH}$ and $\mathrm{PCO}_{2}$ of the donated blood were within physiologic range when the blood was added to the oxygenator for the experimental animal.

Blood samples were obtained simultaneously from the aortic root and coronary sinus at the various times described previously (i.e., prebypass control and cardioplegia intervals 1, 2, and 3). These samples were warmed at $37^{\circ} \mathrm{C}$ and analyzed for hemoglobin concentration, $\mathrm{pH}, \mathrm{PCO}_{2}, \mathrm{PO}_{2}$, and oxyhemoglobin saturation with an automated blood gas analyzer and $\mathrm{Co}-$ Oximeter (model BGE-1400 blood gas analyzer and model 482 Co-Oximeter, Instrumentation Laboratory, Lexington, Mass.). Serum lactate concentration was determined for the high-hemoglobin cardioplegia group by means of an enzymatic spectrophotometric assay (Sigma Chemical Company, St. Louis, Mo.). Transmyocardial lactate gradients and arterial-venous oxygen content differences were calculated from these data. A summary of the experimental protocol is shown schematically in Fig. 1.

Statistical analysis. The data were analyzed with SAS-PC software (SAS Institute, Inc., Cary, N.C.) and then displayed with Sigma Plot software (Jandel Scientific, Corte Madera, Calif.). Statistical comparisons were made with analysis designs contained in the General Linear Models procedure of SAS-PC. Duncan's multiple range test was used to scan the variables across the entire study for significant differences between sam- 


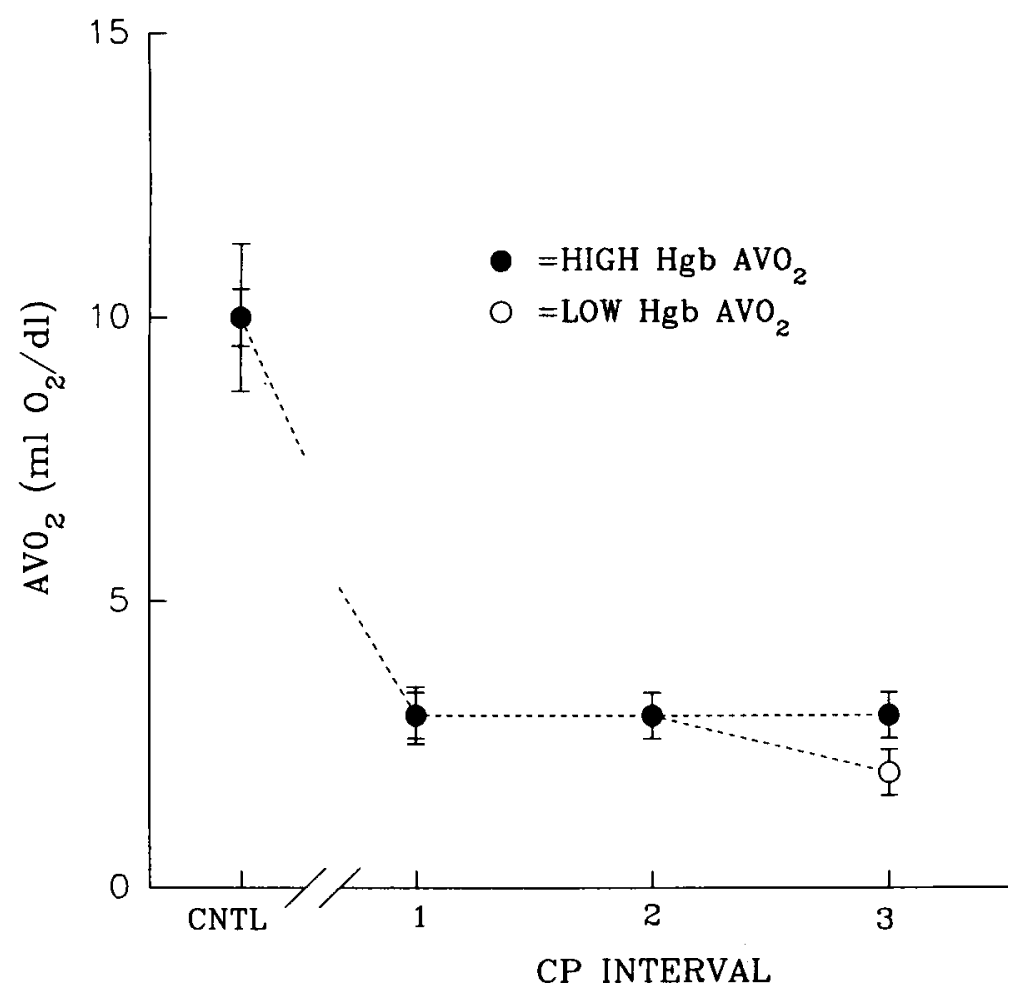

Fig. 3. There was no discernible difference in the volume of oxygen that dissociated from hemoglobin during the ischemic intervals of cardioplegic arrest between the high- and low-hemoglobin cardioplegia groups. $\left(\mathrm{AVO}_{2}=\mathrm{Aortic}\right.$ root - Coronary sinus oxygen content.)

ples. A least squares means test was used to evaluate specific preplanned comparisons. The level of significance chosen for this study was $p<0.05$.

\section{Results}

The addition of donor blood to the perfusate produced a hemoglobin concentration of $7 \pm 1 \mathrm{gm} / \mathrm{dl}$ in the highhemoglobin cardioplegia group versus $4 \pm 1 \mathrm{gm} / \mathrm{dl}$ for the low-hemoglobin cardioplegia group $(p<0.05$, high versus low hemoglobin concentration; all values expressed as mean \pm standard error of the mean). Blood incompatibilities (e.g., agglutination or unusual hemolysis) were not noted in any of the animals.

The results of the present study are similar to findings from the previous study of oxygen uptake during cardioplegic arrest reported by this laboratory. ${ }^{1}$ Dissolved oxygen was taken up during the ischemic intervals of cardioplegic arrest. This caused a decrease in coronary sinus $\mathrm{PO}_{2}$ compared with aortic root $\mathrm{PO}_{2}$ in the samples obtained 5 seconds after cardioplegia intervals 1,2 , and 3 in both groups. Despite a trend toward higher arterialvenous $\mathrm{PO}_{2}$ gradients in the high-hemoglobin group during the ischemic intervals, these intergroup differences did not attain statistical significance (Fig. 2).
Oxyhemoglobin dissociation occurred in both experimental groups during the ischemic intervals of cardioplegic arrest. However, no significant differences were detectable between the high- and low-hemoglobin groups in the arterial-venous oxygen content differences for samples taken at cardioplegia intervals 1,2 , and 3 ( $p$ values: control $=0.78$; cardioplegia interval $1=0.95$; interval $2=0.56$; and interval $3=0.12$ ) (Fig. 3 )

A trend toward higher coronary sinus hemoglobin oxygen saturations was observed for samples obtained in the high-hemoglobin group at cardioplegia intervals 1,2 , and 3. However, these differences did not attain statistical significance (Fig. 4).

The transmyocardial proton gradients $\left(\Delta \mathrm{H}^{+}\right)$for both experimental groups are shown in Fig. 5. This variable represents the transmural gradient for free (i.e., nonbuffered) protons. The ordinate is displayed as the negative $\log$ of the proton gradient. The formula used to derive the transmyocardial proton gradient is as follows:

$$
\Delta \mathrm{H}^{+}=\left(-\log _{10}\left[10^{-\mathrm{CS} \mathrm{pH}}-10^{-\mathrm{ART} \mathrm{pH}}\right]\right)
$$

where $\mathrm{CS}$ and $\mathrm{ART} \mathrm{pH}$ are coronary sinus $\mathrm{pH}$ and arte- 


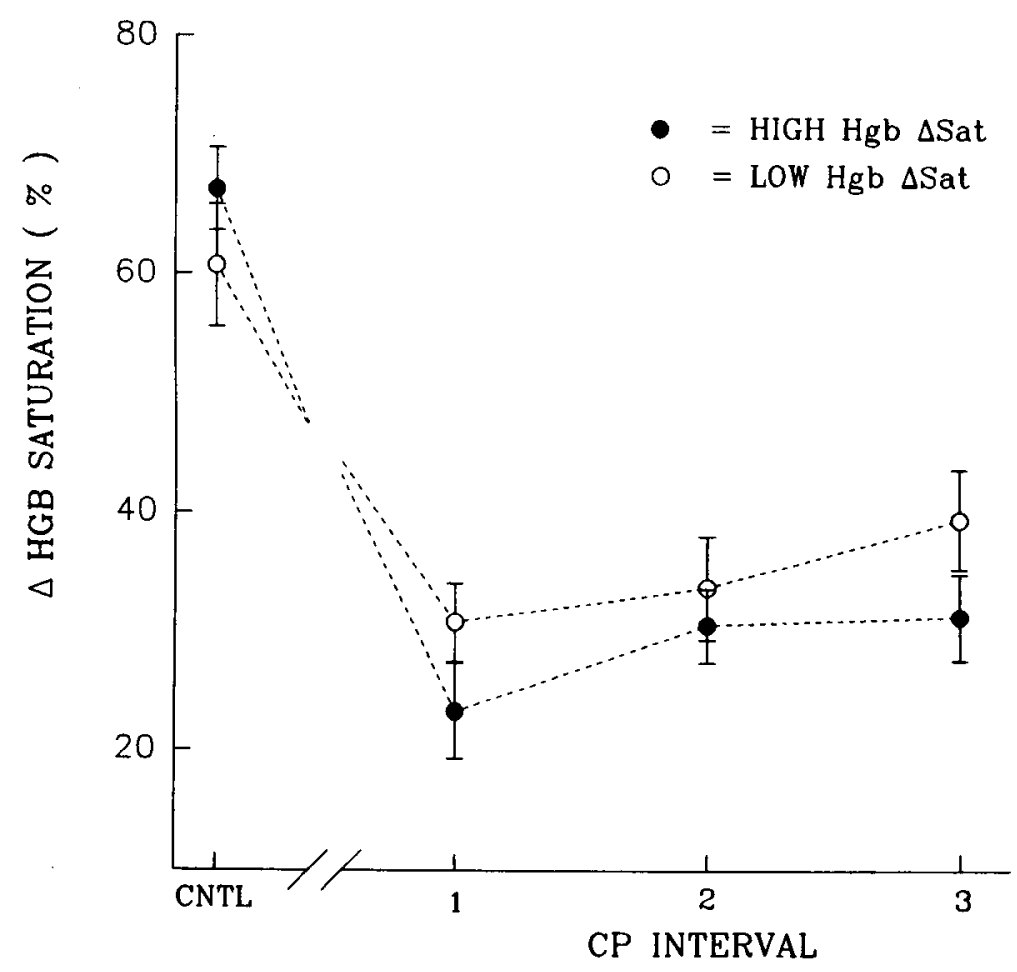

Fig. 4. There was an insignificant trend for higher coronary sinus hemoglobin saturations, and therefore a lower transmyocardial gradient for hemoglobin saturation, in the high hemoglobin group. ( $\triangle H G B S A T U R A T I O N$ $=$ Aortic root - Coronary sinus hemoglobin saturation.)

rial $\mathrm{pH}$. A significantly higher number of free protons were present after cardioplegia intervals 1 and 3 in the low-hemoglobin cardioplegia group. A similar difference noted for cardioplegia interval 2 did not attain significance $(p=0.18)$.

Lactate determinations showed a positive transmyocardial lactate gradient for the high-hemoglobin group before cardiopulmonary bypass. However, the transmyocardial lactate gradients for the samples obtained at cardioplegia intervals 1, 2, and 3 were all negative (Fig. 6).

\section{Discussion}

The hypothesis of the present study is that more oxygen will dissociate from hemoglobin in a cardioplegic solution with a higher hemoglobin content than from a cardioplegic solution with a lower hemoglobin content during the ischemic (i.e., nonperfused) phases of hypothermic cardioplegic arrest. The postulated mechanism for the release of oxygen tightly bound to hemoglobin in a hypothermic alkalotic cardioplegic solution is an acute increase in the $\mathrm{P}_{50}{ }^{*}$ of hemoglobin that is dependent on

*Oxygen tension at which hemoglobin is half saturated with oxygen. myocardial rewarming and the local generation of $\mathrm{H}^{+}$ during the ischemic phase of cardioplegic arrest. ${ }^{1}$ Because the erythrocyte component of a blood cardioplegic solution provides buffering capacity, ${ }^{4,5}$ it was further hypothesized that the increment in oxygen provided by the solution with the higher hemoglobin concentration would be less than the increment predicted by a simple ratio of hemoglobin concentrations in the cardioplegic solution. This prediction regarding the amount of oxygen provided by a higher concentration of hemoglobin in a hypothermic, alkalotic blood cardioplegic solution is consistent with the negligible effect of hematocrit in the cardioplegic solution documented in a previous study of postcardioplegia mechanical function, ${ }^{2}$ as well as other studies that demonstrated diminishing benefit for a blood cardioplegic solution as compared with an oxygenated crystalloid cardioplegic solution as the temperature of the cardioplegic solution decreased. ${ }^{6,7}$

The data from the present study showed that increasing the hemoglobin concentration of a $4^{\circ} \mathrm{C}$ blood cardioplegic solution from $4 \pm 1 \mathrm{gm} / \mathrm{dl}$ in the lowhemoglobin cardioplegia group to $7 \pm 1 \mathrm{gm} / \mathrm{dl}$ in the high-hemoglobin cardioplegia group had no discernible effect on the volume of oxygen that dissociated from 


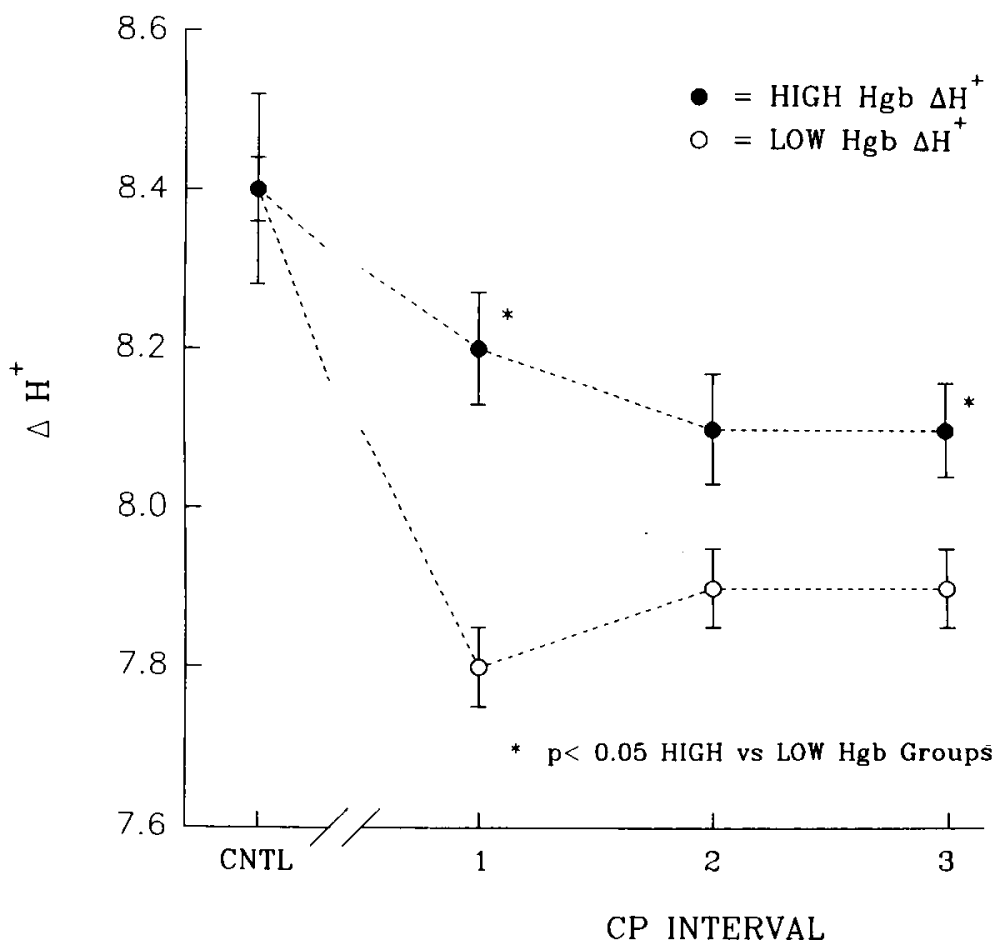

Fig. 5. More free protons were generated (i.e., there was a greater change in $\mathrm{pH}$ ) during cardioplegic arrest in the low-hemoglobin group than in the high-hemoglobin group. This difference was statistically significant $(\mathrm{p}<0.05)$ for cardioplegia intervals 1 and $3 .\left(\Delta \mathrm{H}^{+}=\left[-\log _{10}\left(10^{-\mathrm{CS} \mathrm{pH}}-10^{-\mathrm{ART} \mathrm{pH}}\right)\right].\right)$

hemoglobin during the ischemic intervals of cardioplegic arrest. The trend toward higher coronary sinus hemoglobin saturation for the samples taken after cardioplegia intervals 1 through 3 in the high-hemoglobin group corroborate this finding.

The absence of a demonstrable difference in the volume of oxygen that dissociated from the test solutions was associated with a decreased generation of free protons (i.e., less shift in $\mathrm{pH}$ ) during the ischemic intervals of cardioplegic arrest in the high-hemoglobin group as compared with the low-hemoglobin group. Note that the total number of protons generated during the ischemic interval of cardioplegic arrest was not measured in this study.

Lactate was generated by the heart during all ischemic intervals in the high-hemoglobin group. The generation of lactate during ischemic intervals in the high-hemoglobin group suggests that myocardial oxygen uptake and use remained below the maximal level possible despite the greater volume of oxygen carried to the myocardium by the additional hemoglobin. Presumably, the shift in the $P_{50}$ necessary for oxyhemoglobin dissociation under the conditions of cardioplegic arrest was inhibited by the buffering action of the erythrocytes.

Limitations in the methods and several assumptions used in this study should be recognized. The sampling technique provides information regarding time-related changes in oxyhemoglobin dissociation that is superior to information from pooled coronary sinus samples. However, the method fails to distinguish regional differences in myocardial oxygen use that may be important and does not detect the changes that occur moment by moment during the ischemic intervals of cardioplegic arrest. Because of these limitations, the mechanism for oxyhemoglobin dissociation in the setting of an extremely low $P_{50}$ (i.e., the $P_{50}$ of an alkalotic, hypothermic blood cardioplegic solution) remains speculative.

This study also assumes that lactate production by the myocardium is dependent solely on oxygen delivery and uptake. This assumption ignores the many other factors that influence lactate metabolism. ${ }^{15-17}$ In the case of hypothermic cardioplegic arrest, hypothermia may adversely affect the activity of enzymes that are involved in aerobic metabolism. Thus excess lactate might be released from hypothermic myocytes even if adequate oxygen were available within the myocytes.

This study used an intact animal preparation. Noncoronary collateral blood flow to the myocardium during cardioplegic arrest was not measured, and this unac- 


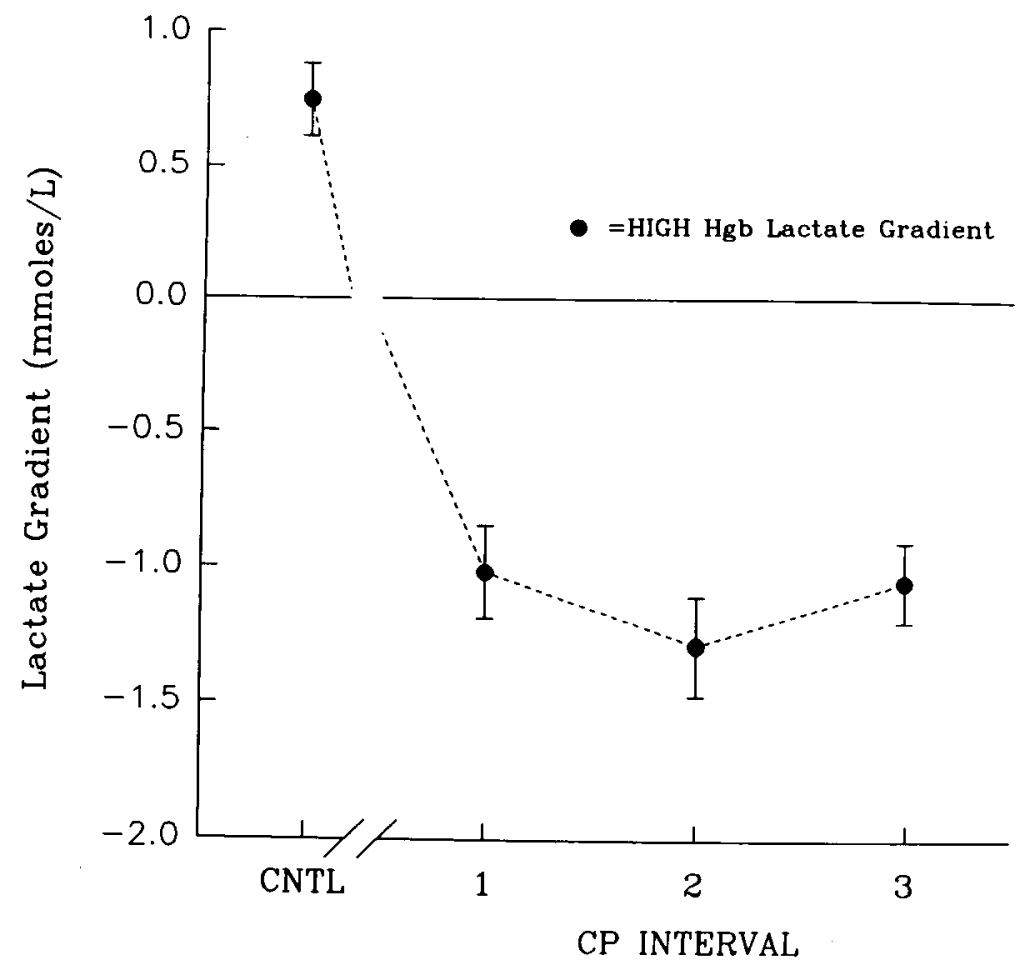

Fig. 6. The lactate gradient was negative for all three cardioplegia intervals in the high hemoglobin group. (Lactate gradient $=$ Aortic root - Coronary sinus lactate.)

counted flow may have affected our observations. However, the balloon in the coronary sinus presumably minimized the washout of cardioplegic solution during the ischemic interval. Furthermore, the cardioplegic solution and the systemic perfusate had a higher hemoglobin concentration in the high-hemoglobin group than in the lowhemoglobin group. Thus, if a difference in the transmyocardial oxygen content gradient existed between the high- and low-hemoglobin groups, it should have been seen despite the effect of collateral flow.

Although there were advantages to using a balloontipped coronary sinus catheter, there were also disadvantages. The balloon probably occluded the veins draining the posterior septum and right ventricle. Therefore, the data did not truly represent global cardiac venous samples. The pressure at the catheter tip during infusion of the cardioplegic solution was not measured. Negative or positive variation from $0 \mathrm{~mm} \mathrm{Hg}$ could influence regional myocardial blood flow distribution, but this influence should have been equal in the two groups tested.

These data should not be construed as evidence for abandoning blood cardioplegia or drastically decreasing hemoglobin content in the cardioplegic solution. Several studies have demonstrated that oxygen delivered from hemoglobin during cardioplegic arrest is impor- tant. $^{2,18,19}$ Moreover, the other non-oxygen-related beneficial effects of erythrocytes make their inclusion in cardioplegic solutions worthwhile. ${ }^{3-5,20}$ These non-oxygenrelated benefits include the buffering of free $\mathrm{H}^{+}$by erythrocyte proteins (e.g., hemoglobin) and the oxygen free radical scavenging capacity of erythrocytes.

The data from the present study emphasize the inherent limitations of unmodified erythrocyte hemoglobin in hypothermic alkalotic cardioplegic solutions: These limitations may be obviated by the development of methods that increase the dissolved oxygen content of the cardioplegic solution or the discovery of methods to decrease the affinity of hemoglobin for oxygen under conditions of hypothermia and alkalosis. Whether improving the efficiency of oxygen transfer from hypothermic blood-based cardioplegic solutions to the myocardium will ultimately result in improved myocardial protection during hypothermic cardioplegic arrest remains to be tested. However, the previous experience with perfluorocarbon-based cardioplegic solutions suggests that such an improvement will occur.

Physically dissolved oxygen in a blood cardioplegic solution can be increased by adding a perfluorocarbon emulsion. Current-generation perfluorocarbon emulsions contain four to five times the concentration of perfluoro- 
carbon present in the previous generation of emulsions; thus they will carry four to five times as much dissolved oxygen as previous perfluorocarbon emulsions. ${ }^{21}$ The potential for this line of development is great and has been noted by others. ${ }^{22}$

Another possibility for increasing myocardial oxygen use during hypothermic cardioplegic arrest is to use a free hemoglobin additive engineered to have an acceptably high $\mathrm{P}_{50}$ (i.e., in the range of 20 to $30 \mathrm{~mm} \mathrm{Hg}$ ) at the temperature and $\mathrm{pH}$ conditions found in hypothermic cardioplegic solutions. This notion also has great potential but awaits the development of methods for protein modification required to modulate the oxygen-binding activity of hemoglobin, as well as the discovery of methods to neutralize the toxicity of free hemoglobin.

We express our gratitude to Fred D. Wallace, Ron Brown, and Jefferson Dudelston for their expert technical assistance. We also thank Lynne Rich for her assistance in the preparation of this manuscript.

\section{REFER E N CES}

1. Holman WL, Spruell RD, Digerness SB, Dudelston J, Pacifico AD. Oxyhemoglobin dissociation during hypothermic cảrdioplegia arrest. Circulation 1992;86(Suppl I):II339-45.

2. Rousou JA, Engelman RM, Breyer RH, Otani H, Lemeshow S, Das DK. The effect of temperature and hematocrit level of oxygenated cardioplegic solutions on myocardial preservation. J THORAC CARdiovasc SuRg 1988;95:62530.

3. Bing OHL, LaRaia PJ, Gaasch WH, Spadaro J, Franklin A, Weintraub RM. Independent protection provided by red blood cells during cardioplegia. Circulation 1982;66:81-4.

4. Illes RW, Silverman NA, Krukenkamp IB, Yusen RD, Chausow DB, Levitsky S. The efficacy of blood cardioplegia is not due to oxygen delivery. J THORAC CARDIOvasC SURG 1989;98:1051-6.

5. Illes R, Silverman N, Krukenkarmp I, Nakamura H, Levitsky S. Role of the red blood cell in oxygenated cardioplegia [Abstract]. FASEB J 1988;2:A921.

6. Digerness SB, Vanini V, Wideman FE. In vitro comparison of oxygen availability from asanguineous and sanguineous cardioplegia media. Circulation 1981;64:80-3.

7. Magovern GJ Jr, Flaherty JT, Gott VL, Buckley BH, Gardner TJ. Failure of blood cardioplegia to protect myocardium at lower temperatures. Circulation 1982;66:60-7.

8. Rousou JH, Dobbs WA, Engelman RM. Fluosol cardiople- gia: a method of optimizing aerobic metabolism during arrest. Circulation 1982;66(Suppl):I55-9.

9. Johnson DL, Greene PS, Gott VL, Gardner TJ. New pluronic-free perfluorocarbon cardioplegia improves myocardial oxygenation. Circulation 1988;78(Suppl):III 153-7.

10. Novick RJ, Stefaniszyn HJ, Michel RP, Burdon FD, Salerno TA. Protection of the hypertrophied pig myocardium: a comparison of crystalloid, blood, and Fluosol-DA cardioplegia during prolonged aortic clamping. J THORAC CARdiovasc SuRG 1985;89:547-66.

11. Magovern GJ Jr, Flaherty JT, Gott VL, Bulkley BH, Gardner TJ. Optimal myocardial protection with Fluosol cardioplegia. Ann Thorac Surg 1982;34:249-57.

12. Flaherty JT, Jaffin JH, Magovern GJ, et al. Maintenance of aerobic metabolism during global ischemia with perfluorocarbon cardioplegia improves myocardial preservation. Circulation 1984;69:585-92.

13. Kanter KR, Jaffin JH, Ehrlichman RJ, Flaherty JT, Gott VL, Gardner TJ. Superiority of perfluorocarbon cardioplegia over blood or crystalloid cardioplegia. Circulation 1981;64(Suppl):II75-80.

14. Tabayashi K, McKeown PP, Miyamoto M, et al. Ischemic myocardial protection: comparison of nonoxygenated crystalloid, oxygenated crystalloid, and oxygenated fluorocarbon cardioplegic solutions. J THORAC CARDiOvaSC SURG 1988;95:239-46.

15. Cain SM. pH Effects on lactate and excess lactate in relation to $\mathrm{O}_{2}$ deficit in hypoxic dogs. J Appl Physiol 1977; 42:44-9.

16. Sidi A, Davis RF. Lactate extraction fails to accurately reflect regional lactate production in ischemic myocardium. J Cardiothorac Anesth 1989;3:321-8.

17. Apstein CS, Gravino F, Hood WB. Limitations of lactate production as an index of myocardial ischemia. Circulation 1979;60:877-88

18. Follette DM, Mulder DG, Maloney JV, Buckberg GD Advantages of blood cardioplegia over continuous coronary perfusion or intermittent ischemia. J THORAC CARDIOVASC SURG 1978;76:604-19.

19. Vinten-Johansen J, Julian JS, Yokoyama H, et al. Efficacy of myocardial protection with hypothermic blood cardioplegia depends on oxygen. Ann Thorac Surg 1991; 52:939-48.

20. Buckberg GD. Oxygenated cardioplegia: blood is a many splendored thing. Ann Thorac Surg 1990;50:175-7.

21. Reiss JG. Fluorocarbon-based in vivo oxygen transport and delivery systems. Vox Sang 1991;61:225-39.

22. Menasche $P$, Piwnica A. Fluorocarbons in myocardial protection during open-heart surgery: How far is it from myth to reality? J Appl Cardiol 1989;4:47-57. 